\title{
Effects of Surface Modifications on the Mechanical Properties of Reinforced Pineapple Leaf Fibre Polypropylene Composites
}

\author{
Samuel Wadzani Gadzama1 , O. K. Sunmonu², U. S. Isiaku², Abdullahi Danladi² \\ ${ }^{1}$ Scientific Equipment Development Institute (SEDI-Enugu), National Agency for Science \& Engineering Infrastructure, Enugu, Nigeria \\ ${ }^{2}$ Department of Polymer \& Textile Engineering, Ahmadu Bello University, Zaria, Nigeria \\ Email: swadzani@yahoo.com
}

How to cite this paper: Gadzama, S.W., Sunmonu, O.K., Isiaku, U.S. and Danladi, A. (2020) Effects of Surface Modifications on the Mechanical Properties of Reinforced Pineapple Leaf Fibre Polypropylene Composites. Advances in Chemical Engineering and Science, 10, 24-39.

https://doi.org/10.4236/aces.2020.101002

Received: October 6, 2019

Accepted: December 2, 2019

Published: December 5, 2019

Copyright $\odot 2020$ by author(s) and Scientific Research Publishing Inc. This work is licensed under the Creative Commons Attribution International License (CC BY 4.0).

http://creativecommons.org/licenses/by/4.0/

\begin{abstract}
Pineapple Leaf Fibre (PALF) is one of the natural fibres that have high potential in the industry. Natural fibres have become the main alternative source for reinforced polymer composites. The objective of this study is to observe the effect of chemical treatments using Sodium Hydroxide $(\mathrm{NaOH})$ solution, Zinc chloride, Acetic Anhydride and Nitric acid on the mechanical properties of pineapple leaf fibre reinforced polypropylene composites. The tensile test was conducted by using the ASTM D638-10 to obtain the tensile strength (TS) and Young's modulus (YM), Flexural properties were conducted to determine the flexural strength (FS) and flexural modulus (FM) of the reinforced composites using the ASTM D256-10 method, and impact test was conducted to determine the impact strength (IS) of the reinforced composites using the Izod ASTM D790-17 method. From the results obtained, the composites with surface modified PALF fillers show enhanced mechanical properties over the untreated PALF fillers in this order; for TS untreated composite $<$ modified with $\mathrm{NaOH}<$ modified with $\mathrm{C}_{3} \mathrm{H}_{6} \mathrm{O}_{3}<$ modified with $\mathrm{ZnCl}<$ modified with $\mathrm{HNO}_{3}$. For $\mathrm{YM}$ untreated composite $<$ modified with $\mathrm{HNO}_{3}<$ modified with $\mathrm{C}_{3} \mathrm{H}_{6} \mathrm{O}_{3}<$ modified with $\mathrm{NaOH}<$ modified with $\mathrm{ZnCl}$. For FS, untreated PALF/PP composites $<$ modified with $\mathrm{NaOH}<$ modified with $\mathrm{ZnCl}<$ modified with $\mathrm{HNO}_{3}<$ modified with $\mathrm{C}_{3} \mathrm{H}_{6} \mathrm{O}_{3}$. For FM, untreated reinforced PALF/PP composites < modified with $\mathrm{NaOH}<$ modified with $\mathrm{ZnCl}<$ modified with $\mathrm{C}_{3} \mathrm{H}_{6} \mathrm{O}_{3}<$ modified with $\mathrm{HNO}_{3}$. For IS, the untreated reinforced PALF/PP composites < modified with $\mathrm{NaOH}<$ modified with $\mathrm{HNO}_{3}<$ modified with $\mathrm{ZnCl}<$ modified with $\mathrm{C}_{3} \mathrm{H}_{6} \mathrm{O}_{3}$. SEM analysis was carried out on the PALF before the compounding to analyze the effect of the surface modification agents.
\end{abstract}

\section{Keywords}

Surface, Modifications, Properties 


\section{Introduction}

Surface treatment or surface modification increases the surface roughness of natural fibres, it removes lignin, wax and oils of the fiber cell walls and disrupts hydrogen bonding in the network structure. In other words, increment of effective contact area in the fibers creates higher adhesion between the fiber and the polymer matrix, thus, improving the mechanical properties of the composites.

A number of studies have been carried out on applicable fibre surface modification agents, also, a number of researchers have been carried out using different methods to achieve better composites productions. However, no known research has been carried out in running a comparative study of a number of surface modification agents in this case, $\mathrm{ZnCl}, \mathrm{NaOH}, \mathrm{HNO}_{3}$ and $\mathrm{C}_{3} \mathrm{H}_{6} \mathrm{O}_{3}$. This study tends to analyze which of the aforementioned surface modification agents gives PALF/PP reinforced composites with enhanced mechanical properties.

Among the various factors, the final performance of the composite materials depends to a large extent on the adhesion between the polymer matrix and the reinforcement and therefore, on the quality of the interface. To achieve optimum performance of the end product, sufficient interaction between the matrix resin and the cellulosic material is desired. This is often achieved by surface modification of the resin or the filler.

Fibres obtained from pineapple leaves have been previously studied by several authors, Arib et al. [1]; Asim et al. [2]; Chollakup et al. [3]; Devi et al. [4]; George et al. [5]; Hujuri et al. [6]; Shyamal et al. [7]; Smitthipong et al. [8]. Compared to other natural fibres, pineapple leaf fibres (PALF) exhibit superior mechanical properties due to its high cellulose content (around 70\%-82\%) and low microfibrillar angle $\left(14^{\circ}\right)$ [9]. PALF are obtained from the leaves of pineapple plant Ananas comosus, which is a perennial herbaceous plant, widely cultivated in tropical regions of Asia, Central and South America [2]. After harvesting, the pineapple plant has to be removed, generating a large volume of wastes. Wastes consist of leaves of 30 to $90 \mathrm{~cm}$ length [10] [11] and they usually contain herbicides spreading into the air during incineration processes [10]. Moreover, postharvest utilization of pineapple waste would be an alternative and renewable source of natural fibers for industrial purposes since it can add value to pineapple cultivation and reduce negative environmental impacts in the field. Recently, PALF have been studied by several authors as a reinforcement in thermoplastic materials such as low-density polyethylene (LDPE), polypropylene (PP) and starch/poly (lactic acid) (PLA) as reported by [1] [3] [5] [8] [12] [13].

Daramola et al. [14] reported the variation of the ultimate tensile strength for neat Polyester and PALF/Polyester composites. The ultimate tensile strength of the neat polyester was $5.11 \mathrm{MPa}$. It was observed from the results, that, the strength of composites increases linearly from $10 \mathrm{wt} \%$ PALF/Polyester composite to $40 \mathrm{wt} \% \mathrm{PALF} /$ Polyester composite where the optimum value of 29.19 MPa was observed. The incorporation of treated PALFs into polyester matrix at weight fraction of $40 \mathrm{wt} \%$ produced the increase in ultimate tensile strength by 
about $471 \%$, according to their results. The general improvement in the ultimate tensile strength of the treated PALF/Polyester composites is attributed to the enhancement of fibre-matrix interaction and more effective transfer of stress.

Nayan et al. [15] studied the effect of mercerization process on the structural and morphological properties of Pineapple Leaf fibre (PALF) pulp and reported that then tensile strength of the un-mercerized PALF bundle corresponds well with previously reported works. Treatment with $\mathrm{NaOH}$ increases the tensile strength of mercerized PALF due to the removal of impurities and poor crystalline structure of hemicelluloses and lignin. Kasim et al. [16] reported that an alkaline treatment was conducted to enhance the PALF properties. The fabrication was made by compression molding technique with random orientation of PALF. From the experimental study, the results revealed that the voids percentage and interfacial bonding between the PALF and PP affected the mechanical properties of the PALF/PP composite. Kaewpirom and Worrarat [17] studied pineapple leaf fibre-reinforced poly (lactic acid) green composites by blending of poly (lactic acid) polymer and short-length-chopped Pattawia pineapple leaf fibres ( 1 - 3 $\mathrm{mm}$ ) using a twin-screw extruder. Effects of the fibre content and the addition of a coupling agent on mechanical properties and morphology of the composites were investigated.

Flexural modulus is used as an indication of a material's stiffness when flexed. It is well known that the improvement in the modulus depends on the morphology of composites. From the findings of earlier researchers, the flexural modulus of the neat polyester matrix is $500.55 \mathrm{MPa}$. The flexural modulus of the composites follows the same trend with the flexural strength, there was gradual increase in the modulus from $10 \mathrm{wt} \%-20 \mathrm{wt} \%$ fibre loading and begin to decrease as from $30 \mathrm{wt} \%$ - $40 \mathrm{wt} \%$. The optimum value for PALF/Polyester composite is $704.59 \mathrm{MPa}$ which is about $40.76 \%$ obtained at $20 \mathrm{wt} \%$ fibre loading. The reduction in the flexural modulus at higher fibre loading is a result the fibres touching each other which resulted into stress concentration at the tips of PALFs within the matrix.

Flexural strength is the ability of the material to withstand the bending forces applied perpendicular to its longitudinal axis. Generally, in the case of composites, the resistance to interlaminar failure controls the flexural properties. Therefore, high flexural strengths of composite are due to better interfacial adhesion of the fibre-matrix interface, which is a result of the chemical treatment of the PALF that enhanced the fibre-matrix interaction and thereby increased the interfacial bond strength and allowed strongest adhesion at the interface. The decrease in the flexural strength at higher fibre loading ( $40 \mathrm{wt} \%$ in this case) is as a result of non-uniform stress transfer due to PALFs touching each other within the matrix.

Gomze et al. [18] reported that PALF significantly improve the Izod impact energy of epoxy matrix composites. The incorporation of continuous and aligned PALF fabrics results in a marked change with respect to pure epoxy matrix ( $0 \%$ fibre) in which a totally transversal rupture occurs. The crack nucleated at the 
notch will initially propagate transversally through the epoxy matrix, as expected in a polymer. However, when the crack front reaches a fibre, the rupture will proceed through the low strength interface. As a consequence, after the Izod hammer hit the specimen, some fibres will be pulled out from the matrix but, owing to their flexural compliance, the PALF fabric will not break.

Sri and Dadit [19], studied the effect of fibre surface modification on PALF loading and PALF fibre length on the mechanical properties of PALF/epoxy composites they also analyzed the compositions volume fraction of PALF/epoxy composites, which they fixed at $10 / 90 \%, 20 / 80 \%, 30 / 70 \%$ and $40 / 60 \%$. The lengths of the pineapple leaf fibre were fixed to $20 \mathrm{~mm}, 30 \mathrm{~mm}$ and $40 \mathrm{~mm}$. Before the fabrication, PALF underwent alkaline treatment to increase the strength of fibre. All samples underwent three different tests to determine the mechanical properties which are tensile test, impact and bending test. PALF loading of $30 / 70 \%$ with $40 \mathrm{~mm}$ in length shows the higher values of tensile stress, impact and bending which are $22.17 \mathrm{MPa}, 27.63 \mathrm{~J} / \mathrm{m}^{2}$ and $35.53 \mathrm{~N} / \mathrm{mm}^{2}$ respectively.

\section{Materials and Methods}

\subsection{PALF-PP Composite Preparation}

The PALF particles were sieved to obtained uniform particle sizes of an average range of $2-6 \mathrm{~mm}$. This particular size appears to be the most suitable processing size for melt mixing which gives effective reinforcement in Polypropylene as reported by George et al. [5] and Kalia et al. [10]. Melt mixing method was used to mix PALF and PP. Various compositions of PALF in PP were compounded in an injection molding machine as shown in Table 1.

\subsection{Mechanical Properties Test of the PALF Composite}

All the mechanical testing methods that were carried out were based on American Society for Testing and Materials (ASTM). There were three tests performed, namely Tensile Test (ASTM D638-10), Flexural Test (ASTM D256-10) and Impact Test (ASTM D790-17).

\subsubsection{Tensile Property}

The ASTM-D638-10 method was adopted for this research work. The dumbbell shape (Type I) specimen is needed for reinforced composite testing. The testing was done in standard laboratory atmosphere of $37^{\circ} \mathrm{C} \pm 2^{\circ} \mathrm{C}$. A computerized Universal Testing Machine (TUE-C-100), manufactured by Fine Spavy Associates and Engineers PVT Miraj, India, was used at cross-head speed of 50 $\mathrm{mm}$ /minute. Figure 1 shows the Universal Testing Machine used for PALF-PP tensile testing. The specimens were positioned vertically in the grips of the testing machine. The grips were then tightened evenly and firmly to prevent any slippage with gauge length kept at $50 \mathrm{~mm}$. The precise five tested result were chosen for each fibre loading of PALF in PP matrix. 
Table 1. PALF-PP composite weight ratio.

\begin{tabular}{ccc}
\hline PALF Ratio $(\mathrm{g})$ & Polypropylene Ratio $(\mathrm{g})$ & Total Weight Composition $(\mathrm{g})$ \\
\hline 40 & 360 & 400 \\
80 & 320 & 400 \\
120 & 280 & 400 \\
160 & 240 & 400 \\
\hline
\end{tabular}

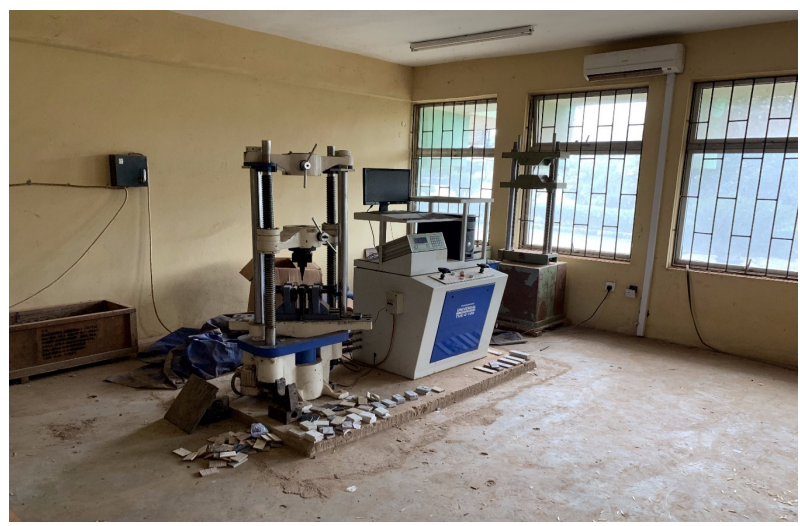

Figure 1. The computerized universal testing machine used in this research.

\subsubsection{Flexural Property}

Flexural strength is the ability of the material to withstand bending forces applied perpendicular to its longitudinal axis. Sometime it is referred as cross-breaking strength where maximum stress developed when a bar-shaped test piece, acting as a simple beam, is subjected to a bending force perpendicular to the bar. The ASTM D790-10 method was adopted for flexural test in this research work. The three-point loading system applied on a supported beam was utilized.

The ASTM D790-10 Procedure A was adopted, where the width and depth of the specimen were measured to the nearest $0.03 \mathrm{~mm}$ at the center of the support span. The test samples were then placed on two supports and load will be applied. The distance of two supports span (L) was fixed at $100 \mathrm{~mm}$. Flexural test was done by A computerized Universal Testing Machine (TUE-C-100), manufactured by Fine Spavy Associates and Engineers PVT Miraj, India at standard laboratory atmosphere of $23^{\circ} \mathrm{C} \pm 2^{\circ} \mathrm{C}$, as shown in Figure 1. This constant cross-head motion appeared to be $5 \mathrm{~mm} / \mathrm{min}$.

\subsubsection{Impact Strength}

The impact properties of the material are directly related to the overall toughness which is defined as the ability to absorb applied energy. The ASTM D256-17 test method A (Izod type) was used for testing. The apparatus involved was Cantilever Beam (Izod Type) Impact Machine and the specimens were notched. Notching was done because it provides a stress concentration area that promotes a brittle rather than a ductile failure. Furthermore, notching also drastically reduces the energy loss due to the deformation of the composite. In the testing, specimens were clamped vertically as a cantilever beam and then struck by a single swing of the pendulum released from a fixed distance from the spe- 
cimen clamp. The line of initial contact is at a fixed distance from the specimen clamp and from the centerline of the notch and on the same face of the notch. This equipment is shown in Figure 2. There are a few parameters that are set according to the standard for instances, Hammer Velocity $=3.46 \mathrm{~m} / \mathrm{s}$ and Hammer Weight $=0.905 \mathrm{~kg}$. The equipment is manufactured by Samuel Denison Limited, England.

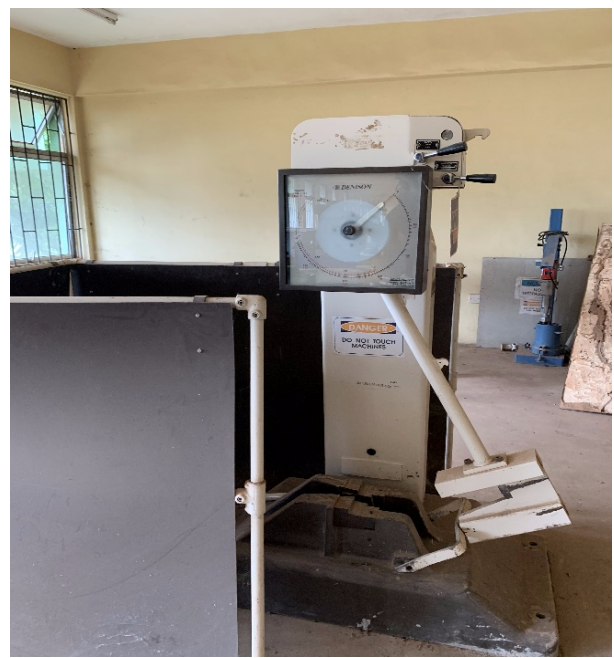

Figure 2. Danison universal pendulum impact system for Izod-Charpy tension and puncture.

\section{Results}

\subsection{The Scanning Electron Microscopy (SEM) of the PALF}

The Scanning electron micrographs of the pineapple leaf fibre (PALF) at different magnifications, showing the different behaviour of the PALF samples (Figure 3 \& Figure 4).

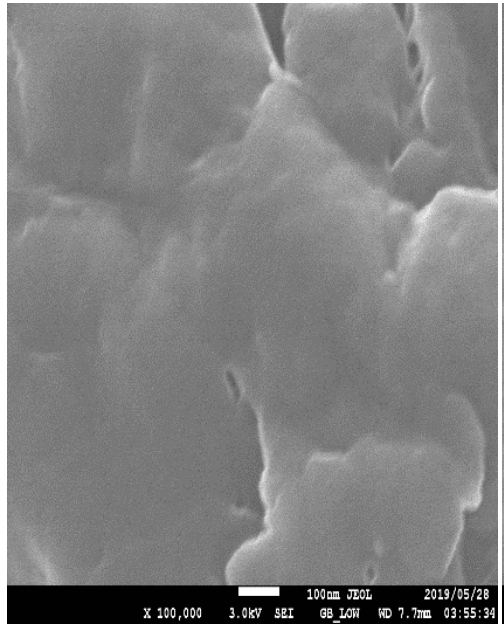

(a)

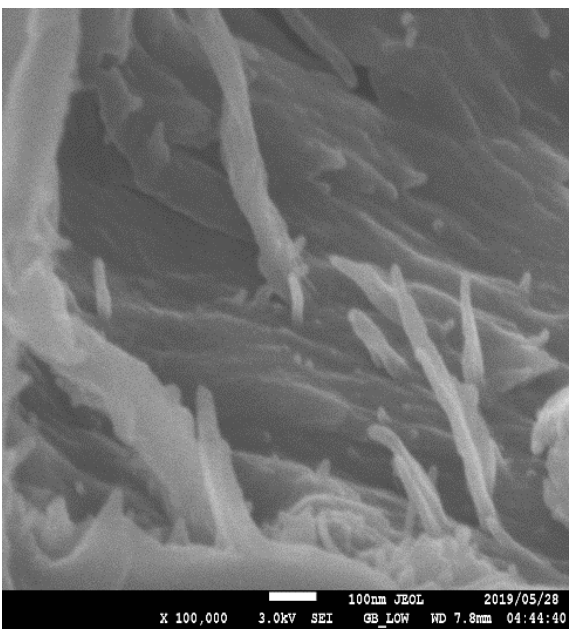

(b)

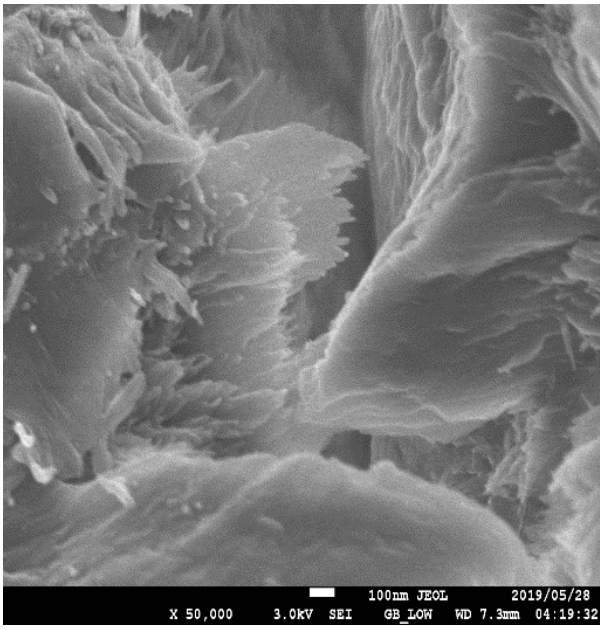

(c)

Figure 3. (a) SEM micrograph of the untreated (unmodified) PALF; (b) The SEM micrograph of the NaOH modified PALF; (c) The SEM micrograph of the $\mathrm{ZnCl}$ modified PALF. 


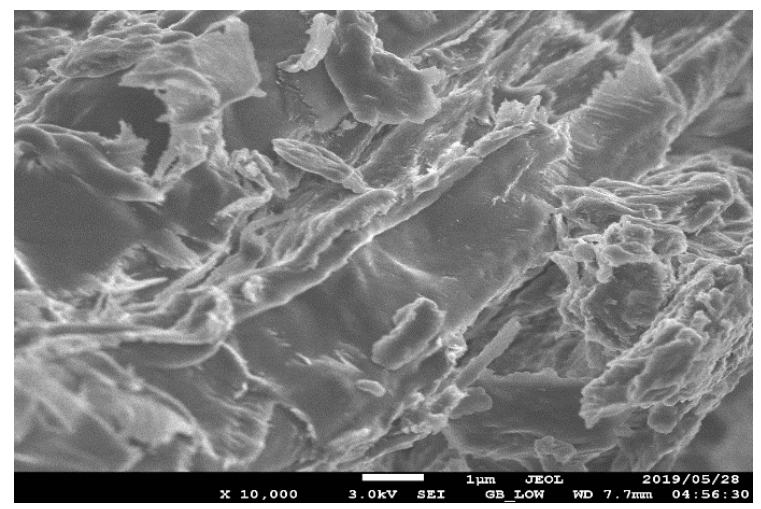

(a)

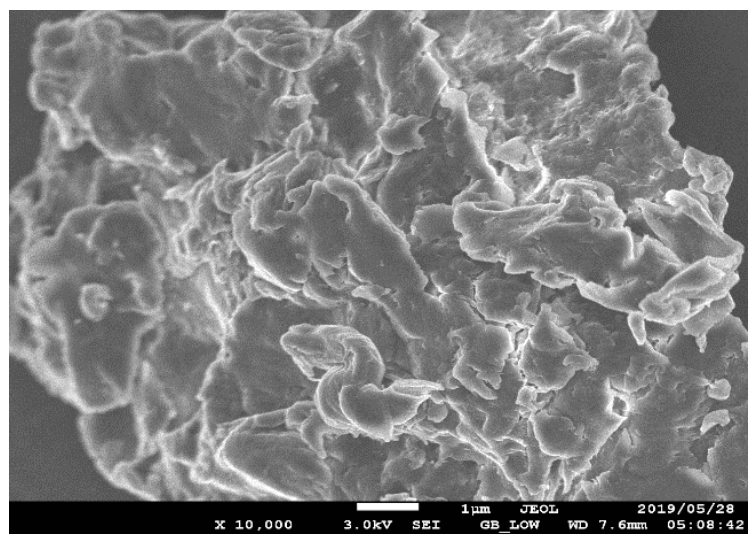

(b)

Figure 4. (a) SEM micrograph of the $\mathrm{C}_{3} \mathrm{H}_{6} \mathrm{O}_{3}$ modified PALF; (b) The SEM micrograph of the $\mathrm{HNO}_{3}$ modified PALF.

\subsection{Tensile Property of the Reinforced PALF Composite Produced}

The results of the test carried out at room temperature and pressure are as given below in form of charts (Figures 5-9).

A plot of tensile property of the untreated (unmodified) PALF/PP composites

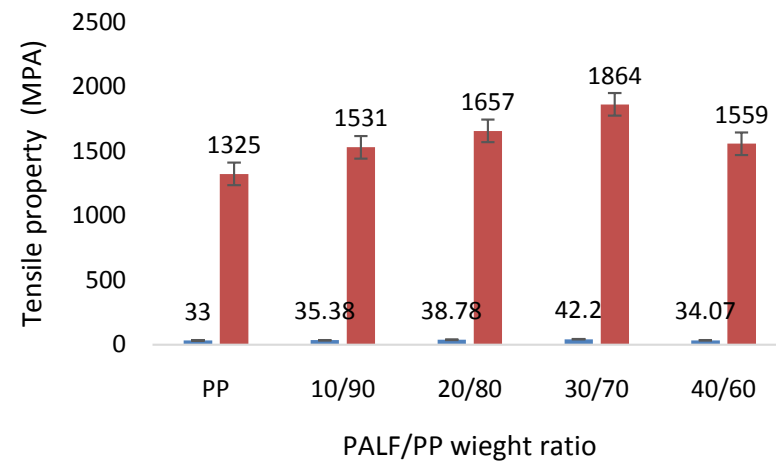

- Tensile strength of the composite at the macro PALF/PP level

Young's modulus of the untreated PALF/PP reinforced composites

Figure 5. Tensile property of the untreated PALF/PP composites. 
A plot of tensile property of $\mathrm{NaOH}$ modified PALF/PP composites

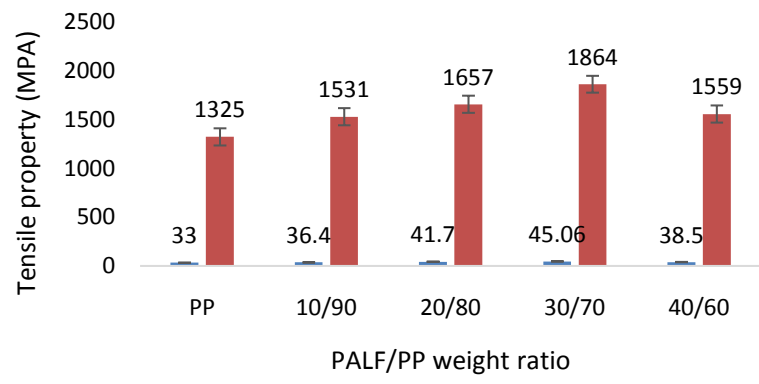

\footnotetext{
- Tensile strength of the $\mathrm{NaOH}$ modified composite at the macro $\mathrm{NaOH}$ modified PALF/PP level

- Young's modulus of the untreated PALF/PP reinforced composites
}

Figure 6. Tensile property of the PALF/PP composites treated with $\mathrm{NaOH}$.

A plot of tensile property of the $\mathrm{ZnCl}$ modified

PALF/PP composites

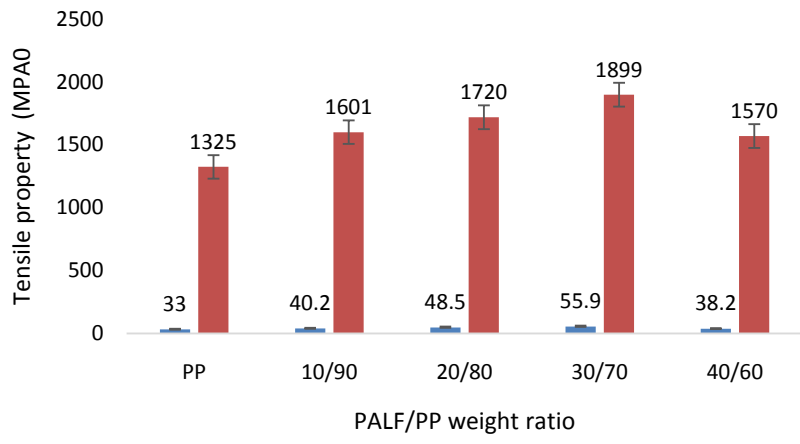

- Tensile strength of the $\mathrm{ZnCl}$ modified reinforced PALF/PP at the macro level

- Young's modulus of the $\mathrm{ZnCl}$ modified macro PALF/PP reinforced composites

Figure 7. Tensile property of the PALF/PP composites treated with $\mathrm{ZnCl}$.

A plot of tensile property of $\mathrm{C}_{3} \mathrm{H}_{6} \mathrm{O}_{3}$ modified PALF/PP composites

2500

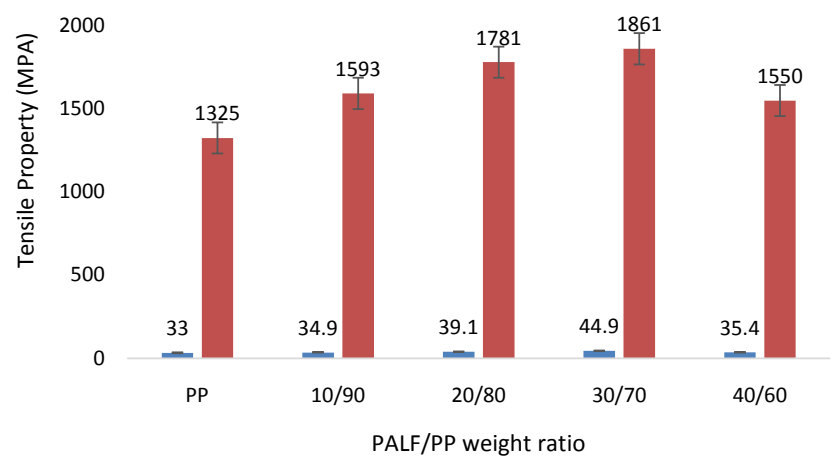

- Tensile strength of the $\mathrm{C} 3 \mathrm{H} 603$ modified reinforced PALF/PP at the macro level

- Young's modulus of the $\mathrm{C} 3 \mathrm{H} 6 \mathrm{O} 3$ modified macro PALF/PP reinforced composites

Figure 8. Tensile property of the PALF/PP composites treated with $\mathrm{C}_{3} \mathrm{H}_{6} \mathrm{O}_{3}$. 
Tensile property of the $\mathrm{HNO}_{3}$ modified PALF/PP composites

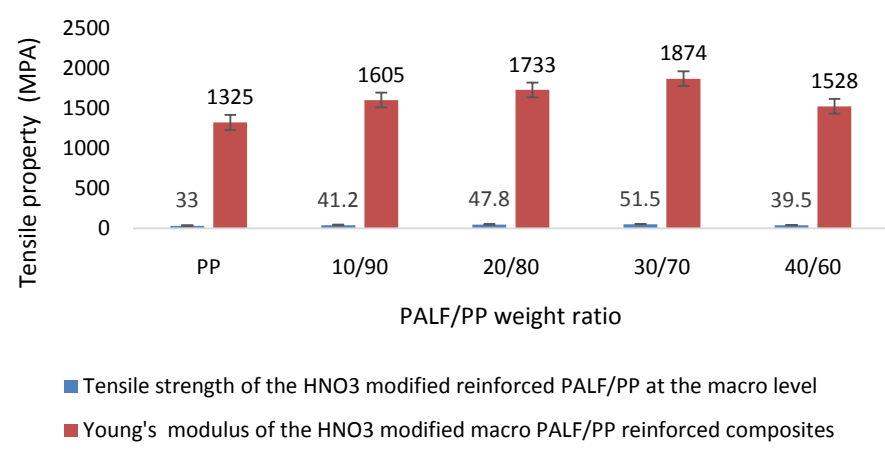

Figure 9. Tensile property of the PALF/PP composites treated with $\mathrm{HNO}_{3}$.

\subsection{The Plots of the Flexural Properties of the PALF/PP Composites}

Figures 10-14 show the flexural properties of the PALF/PP composites, depicting the flexural (FS) and flexural modulus (FM).

A plot of flexural property of the untreated(unmodified) PALF/PP composites

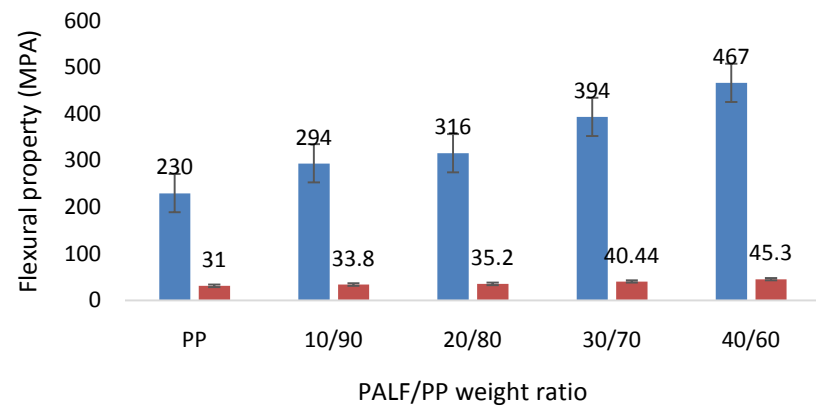

- Flexural modulus of the untreated reinforced macro PALF/PP composites Flexural strength of the untreated macro PALF/PP composites

Figure 10. Flexural property of the untreated PALF/PP composites.

A plot of flexural property of $\mathrm{NaOH}$ modified PALF/PP composites

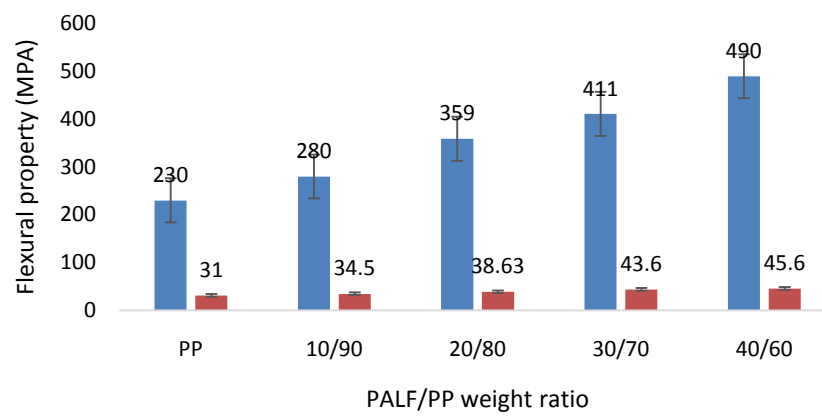

- Flexural modulus of the $\mathrm{NaOH}$ modified reinforced macro PALF/PP composites a Flexural strength of the $\mathrm{NaOH}$ modified macro PALF/PP composites

Figure 11. Flexural property of the PALF/PP composites treated with $\mathrm{NaOH}$. 
A plot of flexural property of $\mathrm{ZnCl}$ modified PALF/PP composites

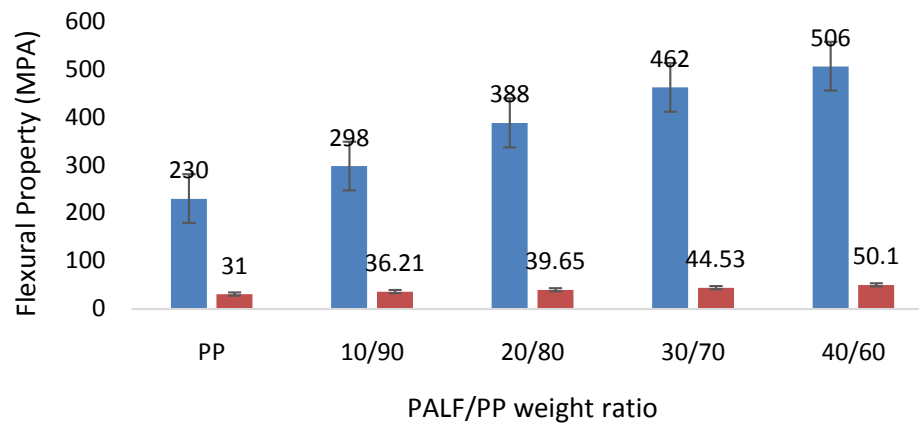

Flexural modulus of the $\mathrm{ZnCl}$ modified reinforced macro PALF/PP composites

- Flexural strength of the $\mathrm{ZnCl}$ modified macro PALF/PP composites

Figure 12. Flexural property of the PALF/PP composites treated with $\mathrm{ZnCl}$.

\section{A plot of flexural property of $\mathrm{C}_{3} \mathrm{H}_{3} \mathrm{O}_{6}$ modified \\ PALF/PP composites}

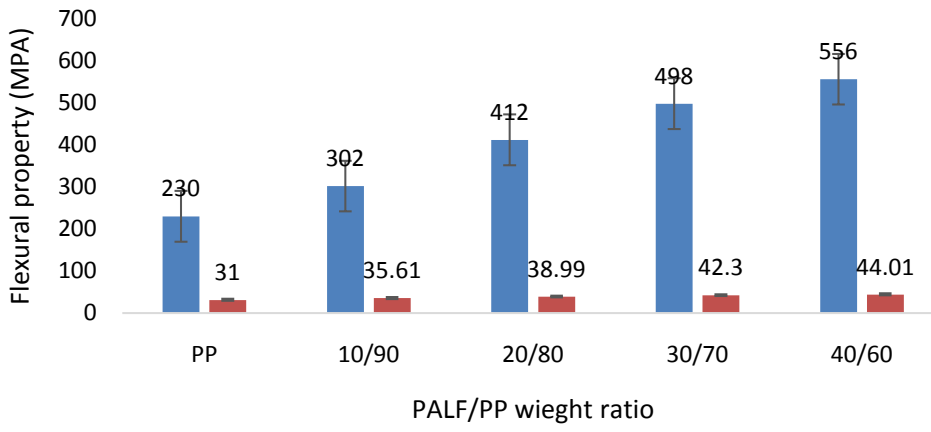

- Flexural modulus of the $\mathrm{C} 3 \mathrm{H} 6 \mathrm{O} 3$ modified reinforced macro PALF/PP composites

a Flexural strength of the $\mathrm{C} 3 \mathrm{H} 603$ modified macro PALF/PP composites

Figure 13. Flexural property of the PALF/PP composite treated with $\mathrm{C}_{3} \mathrm{H}_{6} \mathrm{O}_{3}$.

A plot of flexural property of the $\mathrm{HNO}_{3}$ modfied PALF/PP composites

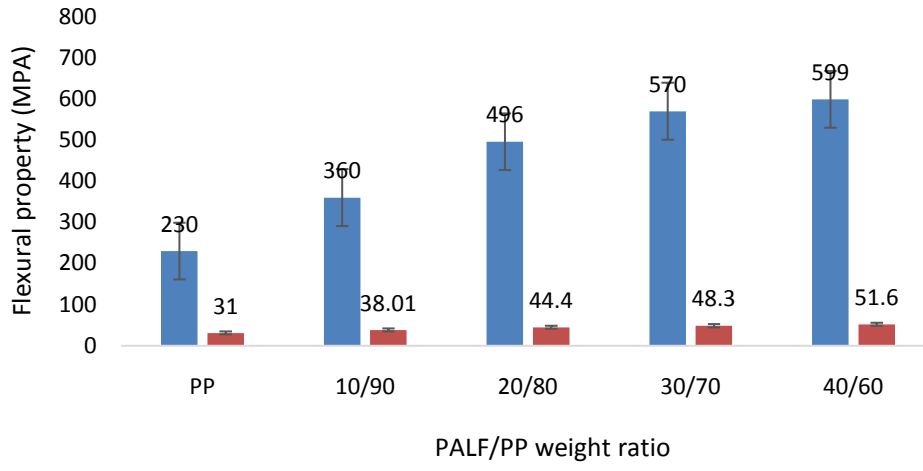

Flexural modulus of the HNO3 modified reinforced macro PALF/PP composites

Flexural strength of the HNO3 modified macro PALF/PP composites

Figure 14. Flexural property of the PALF/PP composites treated with $\mathrm{HNO}_{3}$. 


\subsection{The Impact Strength Plots of the PALF/PP Composites}

Figures 15-19 show the impact strength properties of the PALF/PP composites, depicting the impact strength (IS) of the composites at compositional weight ratios.

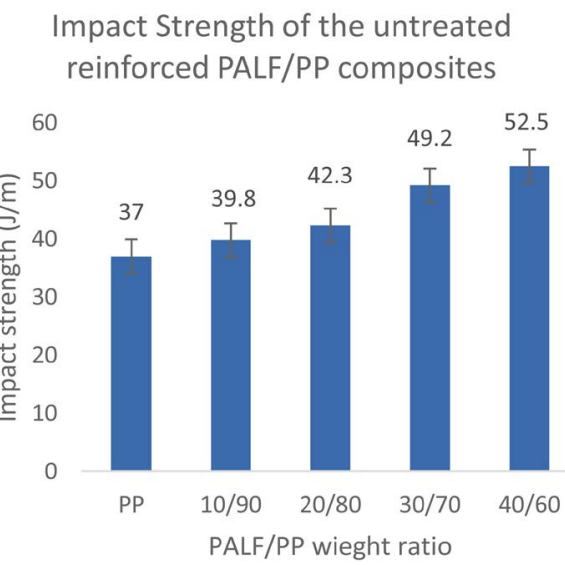

Figure 15. Impact strength of the untreated reinforced PALF/PP composites.

$$
\begin{gathered}
\text { Impact Strength of the } \mathrm{NaOH} \\
\text { modified reinforced PALF/PP } \\
\text { composites }
\end{gathered}
$$

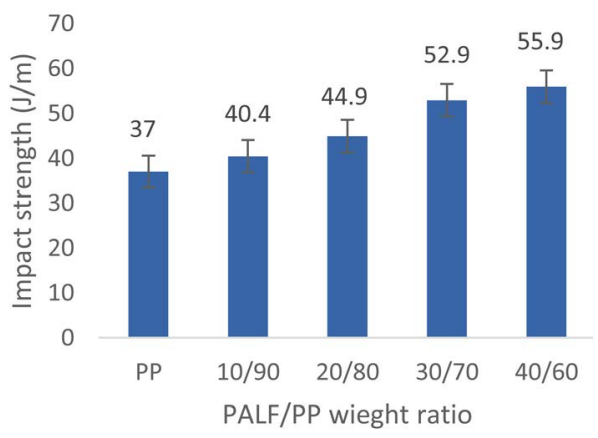

Figure 16. Impact strength of the reinforced PALF/PP composites treated with $\mathrm{NaOH}$.
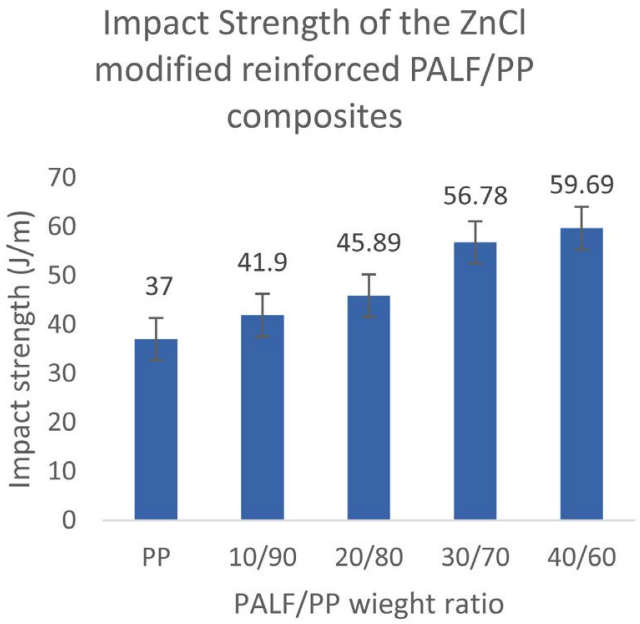

Figure 17. Impact strength of the reinforced PALF/PP composites treated with $\mathrm{ZnCl}$. 


\section{Impact Strength of the $\mathrm{C}_{3} \mathrm{H}_{6} \mathrm{O}_{3}$ modified macro reinforced PALF/PP composites}

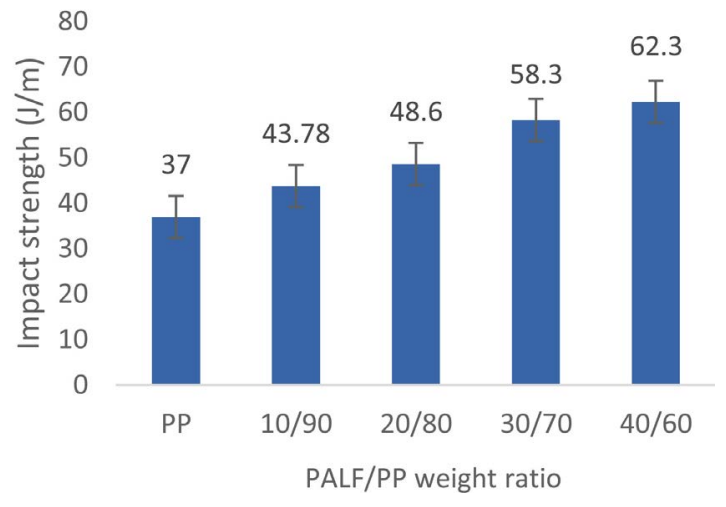

Figure 18. Impact strength of the reinforced PALF/PP composites treated with $\mathrm{C}_{3} \mathrm{H}_{6} \mathrm{O}_{3}$.
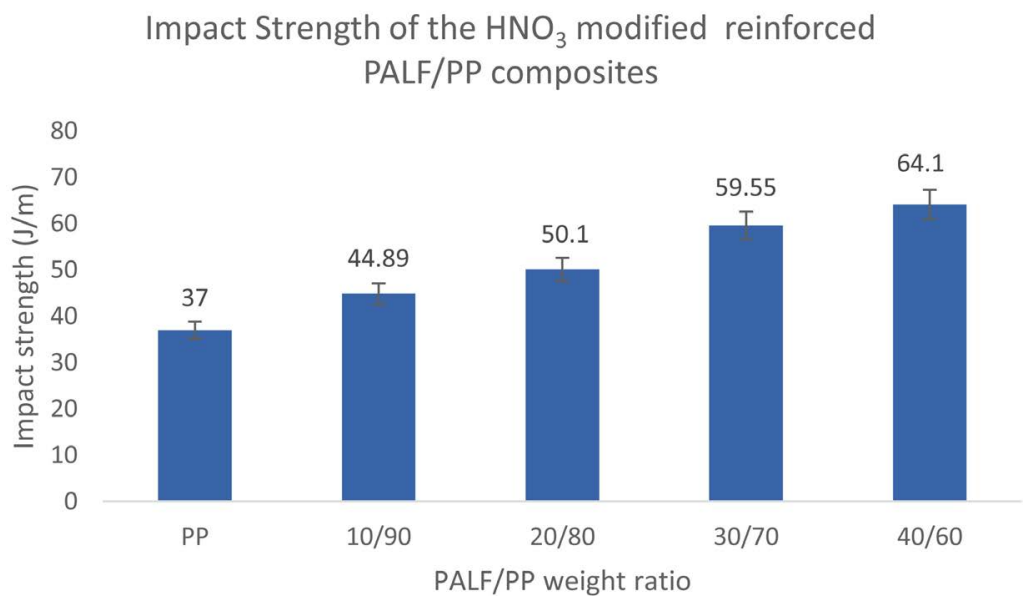

Figure 19. Impact strength of the reinforced PALF/PP composites treated with $\mathrm{HNO}_{3}$.

\section{Results Discussion}

Figures 3(a)-(c), Figure 4(a) and Figure 4(b) show the SEM micrographs of the PALF. Figure 3(a) shows that the surface of the untreated PALF is clogged together, depicting that the PALF cannot readily mix with the matrix there by giving a composite with enhanced properties. Figure 3(b) shows the SEM of the $\mathrm{NaOH}$ modified PALF that is not as clogged as that of Figure 3(a), the micrograph shows the surface of fibre particle that are separated and can readily serve as good reinforcement in the PP matrix. Figure 3(c) shows the SEM micrograph of the $\mathrm{ZnCl}$ modified PALF, here, the micrograph depicts a more dispersed fibre surface that is indicating a better PALF/PP composite. Figure 4(a) represents the SEM of the $\mathrm{C}_{3} \mathrm{H}_{6} \mathrm{O}_{3}$ modified PALF, the PALF samples here shows a surface that is more dispersed when compared to the samples modified with $\mathrm{ZnCl}$ and $\mathrm{NaOH}$. Figure 4(b) shows the SEM micrograph of the $\mathrm{HNO}_{3}$ modified PALF, the samples modified show better separation, thus, depicting samples with expected behavior of composites that will exhibit better performance when com- 
pared with the other samples.

Tensile strength (TS), tensile modulus (TM), flexural strength (FS), flexural modulus (FM), and impact strength (IS) of the prepared composites were studied and the data are given from Figures 5-9. The TS, TM, FS. FM and IS of the PALF/PP composites are as discussed. Figures 5-9 give the results of the tensile property test (TS and TM) of the untreated (control) PALF/PP composites at the macro particle level. From Figure 5, there is a gradual increase in TS and TM as the percentage volume of the filler (PALF) increases from $10 \%$ to $30 \%$, here we had a steady increase of up to $19.28 \%$ as the fibre content increases from $10 \%$ to $30 \%$, there is a sharp decline from $40 \%$ fibre content, similarly, the TM increased in proportional dimension and gave an increase in TM of $22.76 \%$ between the fibre content of $10 \%$ to $30 \%$, where there is an observed decline.

Figure 6 gave a result in similar pattern with an increase in TS by $25.27 \%$ and $\mathrm{TM}$ of $35.40 \%$ for the sample treated with $\mathrm{NaOH}$. Figure 7 depicts an increase by $29.05 \%$ of TS and $43.00 \%$ for TM for samples treated with Zncl, Figure 8 depicts an increase by $48.60 \%$ of TS and $30.72 \%$ of TM for the sample treated with $\mathrm{C}_{3} \mathrm{H}_{6} \mathrm{O}_{3}$. Figure 9 depicts an increase by $49.27 \%$ of TS and $37.93 \%$ for TM for sample treated with $\mathrm{HNO}_{3}$

A similar pattern of percentage increase in the FS and FM of the PALF/PP composites is seen as the fibre percentage volume increases from $10 \%$ to $30 \%$, however, a gradual decline is observed as the percentage fibre volume increases beyond $30 \%$. Figure 10 shows a composite of the untreated (control) PALF/PP, which depicts a steady increase of FS by $34.02 \%$ and FM increase by $74.84 \%$ at the macro particle level. Figure 11 shows a composite treated with $\mathrm{NaOH}$ with an increase in FS and FM of $37.77 \%$ and $90.24 \%$ respectively at the macro particle level. Figure 12 shows a composite treated with $\mathrm{ZnCl}$ with an increase in FS and FM of $38.36 \%$ and $92.52 \%$ respectively at the macro particle level. Figure 13 shows a composite treated with $\mathrm{C}_{3} \mathrm{H}_{6} \mathrm{O}_{3}$ with an increase in FS and FM of $35.82 \%$ and $86.36 \%$ respectively at the macro particle level. Figure 14 shows a composite treated with $\mathrm{HNO}_{3}$ with an increase in FS and FM of 35.76\% and $83.33 \%$ respectively at the macro particle level.

Figures 15-19 gave the results of the impact strength (IS) of the PALF/PP composites at the macro, micro and nano particle levels. It has been observed that the impact strength of the PALF/PP composite increases as the volume of fibre (PALF) increases in the matrix (PP).

From Figure 15, the IS of the untreated PALF/PP composite increased by a percentage of $37.62 \%$ between a fibre volume of $10 \%$ to $40 \%$. From Figure 16 , the IS of the PALF/PP composite treated with $\mathrm{NaOH}$ increased by a percentage of 59.31\% From Figure 17, for PALF/PP composite treated with $\mathrm{ZnCl}$, the IS increased by a factor of $74.29 \%$. From Figure 18, the IS for the PALF/PP composite treated with $\mathrm{C}_{3} \mathrm{H}_{6} \mathrm{O}_{3}$ increased by a factor of $78.54 \%$. From Figure 19, the IS for the PALF/PP composite treated with $\mathrm{HNO}_{3}$, there is a percentage increase of $70.82 \%$.

Kasim et al. [16] investigated the mechanical properties of high impact poly- 
propylene composite reinforced with pineapple leaf fibre from the Josapine cultivar as a function of fibre loading, the results they obtained are in tandem with the ones obtained in this report. From the results, it can be concluded that properties of fiber-reinforced composites depend on many factors i.e., fiber-matrix adhesion, volume fraction of fiber, fiber aspect ratio, fiber orientation as well as stress transfer efficiency of the interface between the matrix and the reinforcement as reported by Chollakup et al. [3] and Arib et al. [1] who investigated the mechanical properties of pineapple-leaf fiber polypropylene composites as a function of volume fraction. They found that flexural and tensile strength increased slightly from $2.7 \%$ to $16.2 \%$, respectively, when the fiber content increased.

The data above means that, with the increase of fibre content, all the mechanical properties increase. PALF composites gained huge mechanical properties over the matrix material and thus indicated good fibre matrix adhesion, more especially for the PALF with chemically enhanced surfaces.

\section{Conclusions}

The superiority of mechanical properties of pineapple leaf fibre can be related to the high content of alpha-cellulose content with low microfibrillar angle $\left(14^{\circ}\right)$. As reinforcing agent PALF has both qualities, that is, high content of alpha-cellulose content with low microfibrillar angle $\left(14^{\circ}\right)$, the results of PALF based polymer composites show excellent stiffness and strength compared to other cellulose based composite materials.

The results obtained are in close agreement with those obtained by earlier researchers. It has been observed that, when the fiber content is higher, properties of reinforced polymer composites tend to decrease due to the increase in fiber to fiber interactions, void content, dispersion and fiber alignment problems. On the other hand, other authors have associated the poor dispersion of the fibers and the void content in polymer composites with the hydrophilic character of natural fibers. Strongly polarized hydroxyl groups found inside natural fibers provide its hydrophilic character.

\section{Conflicts of Interest}

The authors declare no conflicts of interest regarding the publication of this paper.

\section{References}

[1] Arib, R.M.N., Sapuan, S.M., Ahmad, M.M.H.M., Paridah, M.T. and Zaman, H.M.D.K. (2006) Mechanical Properties of Pineapple Leaf Fibre Reinforced Polypropylene Composites. Materials \& Design, 27, 391-396.

https://doi.org/10.1016/j.matdes.2004.11.009

[2] Asim, M., Abdan, K., Jawaid, M., Nasir, M., Dashtizadeh, Z., Ishak, M.R. and Hoque, M.E. (2015) A Review on Pineapple Leaves Fibre and Its Composites. International Journal of Polymer Science, 2015, Article ID: 950567. 
https://doi.org/10.1155/2015/950567

[3] Chollakup, R., Tantatherdtam, R., Ujjin, S. and Sriroth, K. (2011) Pineapple Leaf Fiber Reinforced Thermoplastic Composites: Effects of Fiber Length and Fiber Content on Their Characteristics. Journal of Applied Polymer Science, 119, 1952-1960. https://doi.org/10.1002/app.32910

[4] Devi, L.U., Bhagawan, S.S. and Thomas, S. (1997) Mechanical Properties of Pineapple Leaf Fiber Reinforced Polyester Composites. Journal of Applied Polymer Science, 64, 1739-1748. http://www.scopus.com/ https://doi.org/10.1002/(SICI)1097-4628(19970531)64:9<1739::AID-APP10>3.0.CO $\underline{; 2-\mathrm{T}}$

[5] George, J., Bhagawan, S.S. and Thomas, S. (1997) Improved Interactions in Chemically Modified Pineapple Leaf Fiber Reinforced Polyethylene Composites. Composite Interfaces, 5, 201-223. https://doi.org/10.1163/156855498X00153

[6] Hujuri, U., Chattopadhay, S.K., Uppaluri, R. and Ghoshal, A.K. (2008) Effect of Maleic Anhydride Grafted Polypropylene on the Mechanical and Morphological Properties of Chemically Modified Short-Pineapple-Leaf-Fiber-Reinforced Polypropylene Composites. Journal of Applied Polymer Science, 107, 1507-1516. https://doi.org/10.1002/app.27156

[7] Shyamal, B., Debasis, N. and Sanjoy, D. (2011) Utilization of Pineapple Leaf Agro-Waste for Extraction of Fibre and the Residual Biomass for Vermicomposting. Indian Journal of Fibre \& Textile Research, 36, 172-177.

[8] Smitthipong, W., Tantatherdtam, R. and Chollakup, R. (2015) Effect of Pineapple Leaf Fiber-Reinforced Thermoplastic Starch/Poly(Lactic Acid) Green Composite: Mechanical, Viscosity, and Water Resistance Properties. Journal of Thermoplastic Composite Materials, 28, 717-729. https://doi.org/10.1177/0892705713489701

[9] Mohanty, A.K., Misra, M. and Drzal, L.T. (2005) Natural Fibers, Biopolymers, and Bio-Composites. Taylor \& Francis, Boca Raton, FL. https://doi.org/10.1201/9780203508206

[10] Kalia, S. and Kaith, B.S. (2011) Cellulose Fibers: Bio- and Nano-Polymer Composites: Green Chemistry and Technology. Springer, Berlin.

https://doi.org/10.1007/978-3-642-17370-7

[11] Krauss, B.H. (1949) Anatomy of the Vegetative Organs of the Pineapple, Ananas comosus (L.) Merr. (Continued) II. The Leaf. Botanical Gazette, 110, 333-404. https://doi.org/10.1086/335540

[12] Chattopadhyay, S.K., Khandal, R.K., Uppaluri, R. and Ghoshal, A.K. (2009) Influence of Varying Fiber Lengths on Mechanical, Thermal, and Morphological Properties of Ma- $g$-PP Compatibilized and Chemically Modified Short Pineapple Leaf Fiber Reinforced Polypropylene Composites. Journal of Applied Polymer Science, 113, 3750-3756. https://doi.org/10.1002/app.30252

[13] Kengkhetkit, N. and Amornsakchai, T. (2012) Utilization of Pineapple Leaf Waste for Plastic Reinforcement: 1. A Novel Extraction Method for Short Pineapple Leaf Fiber. Industrial Crops and Products, 40, 55-61.

https://doi.org/10.1016/j.indcrop.2012.02.037

[14] Daramola, O.O., Akintayo, O.S., AdewaleI, A. and Talabi, H.K. (2018) Annals of Faculty of Engineering Hunedoara. University Politehnica Timisonna, Romania.

[15] Nayan, Y. and Skula, A.K. (2013) Processing Copper-Carbon Nanotube Composite Powders by High Energy Milling. Mater Character, 84, 58-66. https://doi.org/10.1016/j.matchar.2013.07.011

[16] Kasim, A.N., Selamt, M.E., Daud, M.A.M., Yaakob, M.Y., Putra, A. and Sivakumar, 
D. (2016) Echancila Properties of Polypropylene Composites Reinforced with Alkaline Treated PALF from Josapine Cultivar. International Journal of Automotive and Mechanical Engineering, 13, 3157-3167.

https://doi.org/10.15282/ijame.13.1.2016.3.0263

[17] Kaewpirom, S. and Worraret, C. (2014) Preparation and Properties of Leaf Fiber Reinforced Poly (Lactic Acid) Green Composite. Fibers and Polymers, 15, 1469-1477. https://doi.org/10.1007/s12221-014-1469-0

[18] Gomez, S., Rendtorff, N.M. and Esteban, F. (2016) Surface Modification of Multiwall Carbon Nanotubes by Sulfonitric Treatment. Applied Surface Science, 379, 264-269. https://doi.org/10.1016/j.apsusc.2016.04.065

[19] Susilowati, S.E. and Sumardiyanto, D. (2018) Assessing Mechanical Properties of PALF Reinforced Composites for Automotive Applications. International Journal of Composites Materials, 8, 57-63. 